\title{
Trend of the incidence of lumbar disc herniation: decreasing with aging in the elderly
}

This article was published in the following Dove Press journal:

Clinical Interventions in Aging

6 August 2013

Number of times this article has been viewed

\author{
Daoyou Ma' \\ Yunbiao Liang' \\ Daoming Wang' \\ Zejiang Liu' \\ Wei Zhang' \\ Tantan Ma' \\ Liang Zhang' \\ Xingjun Lu' \\ Zhiyou Cai ${ }^{2}$ \\ 'Department of Rehabilitation, \\ the Lu'an Affiliated Hospital of \\ Anhui Medical University, Lu'an \\ People's Hospital, Lu'an, Anhui \\ Province, People's Republic of China; \\ ${ }^{2}$ Department of Neurology, the Lu'an \\ Affiliated Hospital of Anhui Medical \\ University, Lu'an People's Hospital, \\ Lu'an, Anhui Province, People's \\ Republic of China
}

Correspondence: Zhiyou Cai Department of Neurology, the Lu'an Affiliated Hospital of Anhui Medical University, Lu'an People's Hospital, No 21 Wanxi West Road, Lu'an, Anhui Province, People's Republic of China, 237005

Tel +865643338520

Fax +865643338520

Email c0909@hotmail.com
Background: Compelling evidence has shown that the incidence of lumbar disc herniation (LDH) increases with age. In this study, retrospective clinical analysis of 601 cases of LDH has been conducted to investigate the role of age in the incidence of LDH in the elderly. The aim of the study is to investigate the relationship between the process of aging and the occurrence of LDH in old adults.

Methods: Clinical cases $(n=601)$ of $\mathrm{LDH}$ were retrospectively analyzed.

Results: The imaging examination with computed tomography and/or magnetic resonance imaging showed the occurrence of degeneration in $\mathrm{LDH}$ patients over 65 years of age. The most common site of LDH is toward the bottom of the spine at L4-L5 and/or L5-S1. The incidence of LDH drops with age in the elderly, especially after the age of 80 years. There is an obvious decrease in LDH in the elderly female.

Conclusion: A decreasing incidence of LDH with aging occurs in the elderly. This investigation indicates that aging is not a contributor to the performance of LDH in the elderly although the incidence of LDH is proportional to age.

Keywords: lumbar disc herniation, incidence, aging

\section{Introduction}

Lumbar disc herniation (LDH), where the most common site is toward the bottom of the spine at L4-L5 or L5-S1 (95\%), makes up the vast majority of spinal disc herniation cases. ${ }^{1,2} \mathrm{LDH}$ occurs when the nucleus in the center of the disc pushes out of its normal space. The nucleus presses against the annulus, causing the disc to bulge outward. With further progress, the nucleus herniates completely through the annulus and squeezes out of the disc, placing pressure on the spinal canal or nerve roots. ${ }^{3}$ In addition, the nucleus releases chemicals that can irritate the surrounding nerves causing inflammation and pain. ${ }^{4-6}$ General symptoms of LDH include one, or a combination, of the following: (1) typical sciatica symptoms such as numbness, weakness, and/ or tingling in the leg and/or foot, leg and/or foot pain, lower back pain, and/or pain in the buttock; and (2) loss of bladder or bowel control, indicating a serious medical condition called cauda equina syndrome.

Normally, daily activities cause the nucleus to press against the annulus. This pressure is not sufficient to cause disease. However, the annulus tends to crack and tear with age and degeneration. With weakness in the annulus, the nucleus may begin to herniate (squeeze) through the damaged annulus. The pressure bulges the annulus outward in the beginning. Eventually, the nucleus herniates completely through the outer ring of the disc. Therefore, it seems that aging is a risk factor and a contributor to 
the incidence of LDH, which increases with age..$^{7-9}$ However, our clinical investigation has recently demonstrated that the trend of the incidence of LDH decreases with aging in the elderly population.

\section{Methods}

\section{Clinical data and analysis}

Subjects $(\mathrm{n}=601)$ aged over 65 years with LDH were included. In this study, all data from January 2006 to April 2013 were collected from the Rehabilitation Department of Lu'an People's Hospital. This study was approved by the research ethics board of Lu'an People's Hospital. Written informed consent was obtained from all participants. Diagnoses were determined by trained rehabilitation therapists based on the 2012 ICD-9-CM Diagnosis Code 722.10 (displacement of lumbar intervertebral disc without myelopathy). The comprehensive diagnostic process included medical history, physical examination, and diagnostic tests. Ruling out other problems such as a tumor or infection, computed tomography scans and/or magnetic resonance imaging were performed to confirm the LDH diagnosis. ${ }^{10,11}$ Finally, retrospective clinical analysis of 601 cases of LDH has been conducted.

\section{Results}

Tables 1 and 2 demonstrated that the clinical presentation of LDH patients is diverse according to the investigation of symptoms, signs, and imaging data. Almost all patients had lumbar vertebrae or paravertebral tenderness. Pain mainly presented in the unilateral leg and/or as lower back pain, accompanied by lumbar motion restriction and sensory disturbances. The imaging examination with computed tomography and/or magnetic resonance imaging manifested the occurrence of degeneration, including spinal stenosis, osteoporosis, vertebral hyperostosis, calcification, and the disappearance of the spine's physiological curvature. In addition, these data indicated that the most common site

Table I Clinical symptoms and signs

\begin{tabular}{|c|c|c|}
\hline Symptoms or signs & Cases & Percentage (\%) \\
\hline $\begin{array}{l}\text { Intervertebral and/or paravertebral } \\
\text { tenderness }\end{array}$ & 576 & 96.3 \\
\hline Unilateral leg and/or lower back pain & 540 & 89.8 \\
\hline Lower extremity pain & 156 & 25.9 \\
\hline Radzikowski sign & 538 & 89.5 \\
\hline Weakness of foot hallux dorsiflexion & 336 & 55.9 \\
\hline Foot drop & 93 & 15.4 \\
\hline Intermittent claudication & 237 & 39.4 \\
\hline Sensory disturbance & 378 & 62.5 \\
\hline
\end{tabular}

Table 2 Imaging feature and distribution

\begin{tabular}{lll}
\hline Imaging feature & Cases & Percentage (\%) \\
\hline Hyperostosis & 60 I & 100.00 \\
Bulge or herniation at L3-L4 & 189 & 31.4 \\
Bulge or herniation at L4-L5 & 228 & 37.9 \\
Bulge or herniation at L5-SI & 268 & 44.5 \\
Bulge or herniation at L3-L4 and L4-L5 & 30 I & 50.0 \\
Bulge or herniation at L4-L5 and L5-SI & $48 \mathrm{I}$ & 80.0 \\
Bulge or herniation at L3-L4, L4-L5, & 297 & 49.4 \\
and L5-SI & & \\
Left side bulge or herniation & 329 & 54.7 \\
Right side bulge or herniation & 227 & 37.7 \\
Central bulge or herniation & 45 & 7.5 \\
Spinal stenosis & 159 & 26.4 \\
Calcification & 79 & 13.1 \\
Osteoporosis & 204 & 33.9 \\
\hline
\end{tabular}

Abbreviations: L, lumbar; S, sacrum.

of LDH is toward the bottom of the spine at L4-L5 and/or L5-S1. In general, Table 3 demonstrated that the incidence of LDH decreases with age in the elderly, especially after 80 years old. There is an obvious decrease in the elderly female (Figure 1). Tables 4-6 showed that the aging factors (hypertension, hyperlipidemia, and diabetes) have no contribution to the incidence of LDH in the elderly.

\section{Discussion}

Our clinical investigation has shown that the clinical presentation of LDH patients was diverse and that the most common site of LDH is toward the bottom of the spine at L4-L5 and/ or L5-S1. Contrary to past reports that the incidence of LDH increases with aging, this study has found that the incidence of LDH has a downward trend with aging in the elderly, especially after 80 years old.

Abnormal activities, such as repetitive bending, twisting, and lifting, can increase abnormal pressure on the nucleus of the disc and injure the annulus, leading to herniation. ${ }^{3,12} \mathrm{LDH}$ occurs as a result of sudden stress, such as from an accident. Poor posture and incorrect lifestyle can place additional stress on the lumbar spine. ${ }^{13,14}$ With aging, discs gradually dry out, lose their strength and resiliency, and easily induce the occurrence of herniation. ${ }^{9,15,16}$ However, our clinical investigation has implicated that the incidence of LDH decreases with

Table 3 Age distribution of patients with lumbar disc herniation

\begin{tabular}{llllllll}
\hline \multicolumn{7}{c}{ Age distribution (years) } & N \\
\cline { 2 - 7 } & $\mathbf{6 5 - 7 0}$ & $\mathbf{7 1 - 7 5}$ & $\mathbf{7 6 - 8 0}$ & $\mathbf{8 I - 8 5}$ & $\mathbf{8 6 - 9 0}$ & $\mathbf{9 1 - 9 5}$ & \\
\hline Male & III & 69 & 78 & 43 & 24 & I & 326 \\
Female & 92 & 68 & 56 & 36 & 22 & I & 275 \\
\hline
\end{tabular}




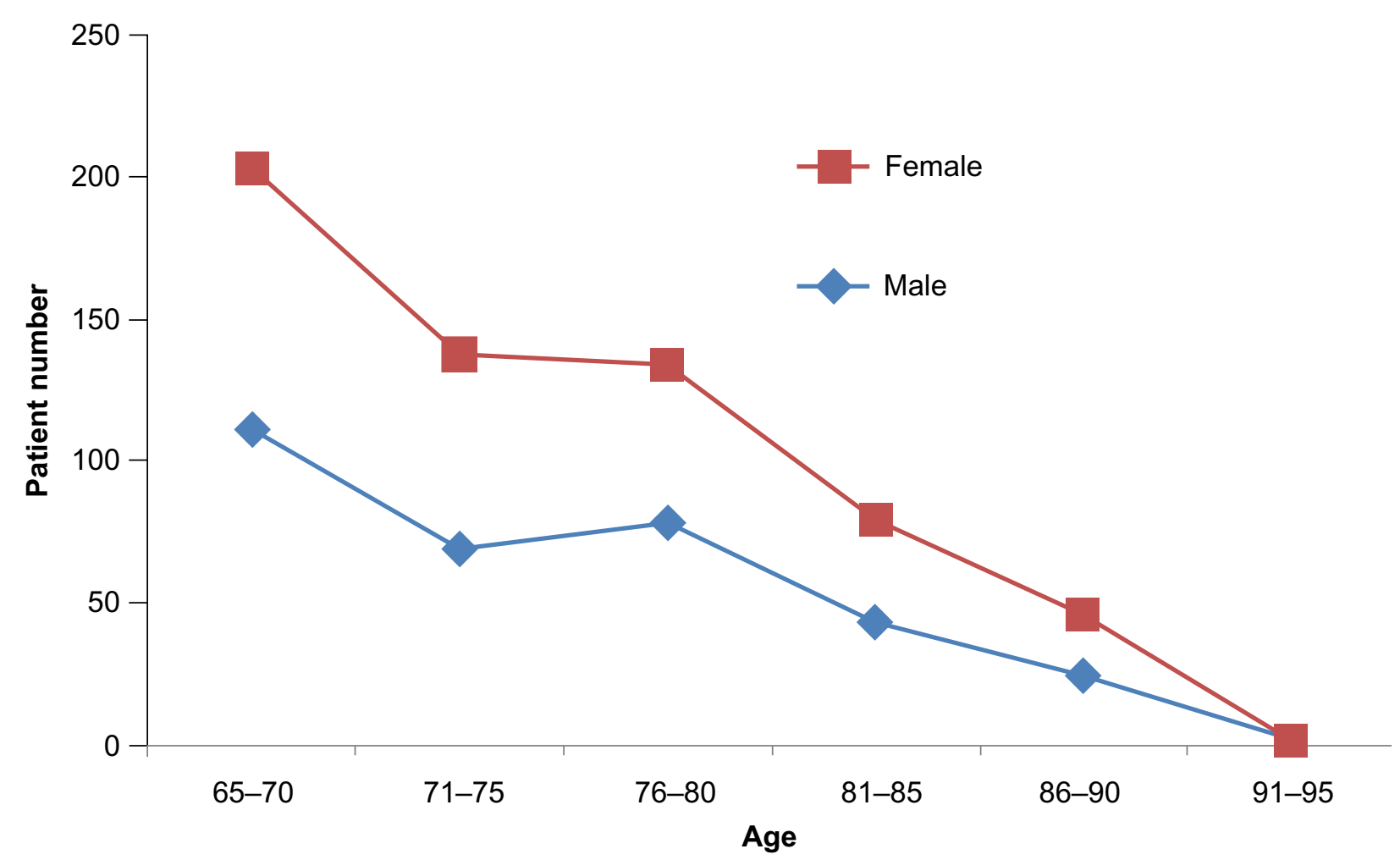

Figure I Age distribution of patients with lumbar disc herniation.

Table 4 Hypertension complication of patients with lumbar disc herniation

\begin{tabular}{lllllll}
\hline & \multicolumn{4}{l}{ Age distribution (years) } \\
\cline { 2 - 7 } & $\mathbf{6 5 - 7 0}$ & $\mathbf{7 I - 7 5}$ & $\mathbf{7 6 - 8 0}$ & $\mathbf{8 I - 8 5}$ & $\mathbf{8 6 - 9 0}$ & $\mathbf{9 1 - 9 5}$ \\
\hline $\mathrm{LDH}$ & 203 & 137 & 134 & $\mathbf{7 9}$ & 46 & 2 \\
$\mathrm{LDH}+$ hypertension & $102(50.3 \%)$ & $69(50.2 \%)$ & $66(49.4 \%)$ & $38(52.1 \%)$ & $22(52.2 \%)$ & I (50.0\%) \\
$P$-value & 0.0912 & 0.0824 & 0.0832 & 0.0928 & 0.0835 & \\
\hline
\end{tabular}

Note: There is no difference in hypertension percentage between each age group.

Abbreviation: LDH, lumbar disc herniation.

Table 5 Hyperlipidemia complication of patients with lumbar disc herniation

\begin{tabular}{|c|c|c|c|c|c|c|}
\hline & \multicolumn{6}{|c|}{ Age distribution (years) } \\
\hline & $65-70$ & 7I-75 & $76-80$ & $81-85$ & $86-90$ & $91-95$ \\
\hline $\mathrm{LDH}$ & 203 & 137 & 134 & 79 & 46 & 2 \\
\hline LDH + hyperlipidemia & $78(38.4 \%)$ & $54(39.4 \%)$ & $53(39.5 \%)$ & $32(40.5 \%)$ & $31(45.6 \%)$ & 0 \\
\hline$P$-value & 0.0846 & 0.0918 & 0.0903 & 0.0726 & - & \\
\hline
\end{tabular}

Note: There is no significant change for the percentage of hyperlipidemia complication between each age group of patients with lumbar disc herniation. Abbreviation: LDH, lumbar disc herniation.

Table 6 Diabetic complication of patients with lumbar disc herniation

\begin{tabular}{|c|c|c|c|c|c|c|}
\hline & \multicolumn{6}{|c|}{ Age distribution (years) } \\
\hline & $65-70$ & $\mathbf{7 1 - 7 5}$ & $76-80$ & $81-85$ & $86-90$ & $91-95$ \\
\hline LDH & 4 & 137 & 134 & 79 & 46 & 2 \\
\hline LDH + diabetes & $4 \mathrm{I}(0.9 \%)$ & $33(24.0 \%)$ & $25(18.6 \%)$ & 17 (2I.5\%) & $9(19.5 \%)$ & 0 \\
\hline$P$-value & 0.0756 & 0.0632 & 0.0780 & 0.0796 & - & \\
\hline
\end{tabular}

Note: There is no significant change in the percentage of diabetic complication between each age group of patients with lumbar disc herniation.

Abbreviation: LDH, lumbar disc herniation. 
aging in the elderly population, especially after 80 years old. Furthermore, there is no relationship between the incidence of LDH in the elderly and the age contributing factors (hypertension, hyperlipidemia, and diabetes). Accordingly, we hypothesized that the volume and inflammation of the nucleus gets lesser since degeneration contributes to atrophy of the nucleus with the aging process. Thus, the pressure from the nucleus will become gradually less, with the result being lower incidence of annulus injury and occurrence of LDH, especially after 80 years old. It seems that the inflammatory effect of the nucleus is stronger than degeneration, and the incidence of LDH is greater before 80 years of age.

Based on the previous discussion, age plays a dual role in LDH pathogenesis. This investigation further suggests that surgery is not preferred in elderly patients with LDH. If it is not a case of acute nerve and spinal cord compression, nonoperative treatment will be used with elderly patients of LDH, such as physical therapy and pain medications. ${ }^{17-19}$ Old adults usually have more herniated disc levels (mostly protrusions). It is better that old adult patients with LDH are treated in a rehabilitation center if they present with degenerative changes. As age progresses, the volume of the nucleus becomes smaller, and the pressure from the nucleus is less. This study also provides new consideration for the future treatment of LDH in the elderly population.

\section{Acknowledgments}

We would like to thank the clinic staff in the Lu'an Affiliated Hospital of Anhui Medical University for their dedication and hard work, and all patients and volunteers for their collaboration.

\section{Disclosure}

All authors report no conflict of interest in this work.

\section{References}

1. Postacchini F, Postacchini R. Operative management of lumbar disc herniation: the evolution of knowledge and surgical techniques in the last century. Acta Neurochir Suppl. 2011;108:17-21.

2. Pouriesa M, Fouladi RF, Mesbahi S. Disproportion of end plates and the lumbar intervertebral disc herniation. Spine J. 2013;13(4):402-407.
3. Strange DG, Fisher ST, Boughton PC, Kishen TJ, Diwan AD. Restoration of compressive loading properties of lumbar discs with a nucleus implant-a finite element analysis study. Spine J. 2010;10(7): 602-609.

4. Guterl CC, See EY, Blanquer SB, et al. Challenges and strategies in the repair of ruptured annulus fibrosus. Eur Cell Mater. 2013;25:1-21.

5. Wei M, Mo SL, Nabar NR, et al. Modification of rat model of sciatica induced by lumber disc herniation and the anti-inflammatory effect of osthole given by epidural catheterization. Pharmacology. 2012;90(5-6): 251-263.

6. Hou SX, Tang JG, Chen HS, Chen J. Chronic inflammation and compression of the dorsal root contribute to sciatica induced by the intervertebral disc herniation in rats. Pain. 2003;105(1-2):255-264.

7. Zigouris A, Batistatou A, Alexiou GA, et al. Correlation of matrix metalloproteinases-1 and -3 with patient age and grade of lumbar disc herniation. J Neurosurg Spine. 2011;14(2):268-272.

8. Matveeva N, Zivadinovik J, Zdravkovska M, Jovevska S, Bojadzieva B. Histological composition of lumbar disc herniations related to the type of herniation and to the age. Bratisl Lek Listy. 2012;113(12):712-717.

9. Dammers R, Koehler PJ. Lumbar disc herniation: level increases with age. Surg Neurol. 2002;58(3-4):209-212.

10. Titlic M, Kolic K, Dolicc K, Boschi V, Josipovic-Jelic Z, BradicHammoud M. Lumbosacral spine herniation - computed tomography diagnostics. Acta Med Croatica. 2010;64(3):201-204. Croatian.

11. Karamouzian S, Eskandary H, Faramarzee M, et al. Frequency of lumbar intervertebral disc calcification and angiogenesis, and their correlation with clinical, surgical, and magnetic resonance imaging findings. Spine (Phila Pa 1976). 2010;35(8):881-886.

12. Martinez Quinones JV, Aso J, Consolini F, Arregui R. Long-term outcomes of lumbar microdiscectomy in a working class sample. Neurocirugia (Astur). 2011;22(3):235-244. Spanish.

13. Pietila TA, Stendel R, Kombos T, Ramsbacher J, Schulte T, Brock M. Lumbar disc herniation in patients up to 25 years of age. Neurol Med Chir (Tokyo). 2001;41(7):340-344.

14. Kim SJ, Kim WR, Kim HS, et al. Abnormal spontaneous activities on needle electromyography and their relation with pain behavior and nerve fiber pathology in a rat model of lumbar disc herniation. Spine (Phila Pa 1976). 2011;36(24):E1562-E1567.

15. Jonsson B, Stromqvist B. Influence of age on symptoms and signs in lumbar disc herniation. Eur Spine J. 1995;4(4):202-205.

16. Lebkowski WJ, Dzieciol J. Degenerated lumbar intervertebral disc. A morphological study. Pol J Pathol. 2002;53(2):83-86.

17. Ishihara $H$, Matsui $H$, Hirano $N$, Tsuji $H$. Lumbar intervertebral disc herniation in children less than 16 years of age. Long-term follow-up study of surgically managed cases. Spine (Phila Pa 1976). 1997;22(17): 2044-2049.

18. Kamanli A, Karaca-Acet G, Kaya A, Koc M, Yildirim H. Conventional physical therapy with lumbar traction; clinical evaluation and magnetic resonance imaging for lumbar disc herniation. Bratisl Lek Listy. 2010;111(10):541-544.

19. Manchikanti L, Singh V, Cash KA, Pampati V, Falco FJ. The role of fluoroscopic interlaminar epidural injections in managing chronic pain of lumbar disc herniation or radiculitis: a randomized, double-blind trial. Pain Pract. Epub December 27, 2012.
Clinical Interventions in Aging

\section{Publish your work in this journal}

Clinical Interventions in Aging is an international, peer-reviewed journal focusing on evidence-based reports on the value or lack thereof of treatments intended to prevent or delay the onset of maladaptive correlates of aging in human beings. This journal is indexed on PubMed Central, MedLine, the American Chemical Society's 'Chemical Abstracts Ser-

\section{Dovepress}

vice' (CAS), Scopus and the Elsevier Bibliographic databases. The manuscript management system is completely online and includes a very quick and fair peer-review system, which is all easy to use. Visit $\mathrm{http}: / /$ www.dovepress.com/testimonials.php to read real quotes from published authors. 